\title{
Estrogen Receptor $\beta$ Activity Modulates Synaptic Signaling and Structure
}

\author{
Deepak P. Srivastava, ${ }^{1}$ Kevin M. Woolfrey, ${ }^{1}$ Feng Liu, ${ }^{3}$ Nicholas J. Brandon, ${ }^{2}$ and Peter Penzes ${ }^{1,2}$ \\ Departments of ${ }^{1}$ Physiology, and ${ }^{2}$ Psychiatry and Behavioral Sciences, Northwestern University Feinberg School of Medicine, Chicago, Illinois 60611, and \\ ${ }^{3}$ Neuroscience Research Unit, Pfizer Global Research and Development, Groton, Connecticut 06340
}

Brain-synthesized estrogen has been shown to influence synaptic structure, function, and cognitive processes. However, the molecular mechanisms underlying the rapid effects of estrogen on the dendritic spines of cortical neurons are not clear. Estrogen receptor $\beta$ (ER $\beta$ ) is expressed in cortical neurons, and $\mathrm{ER} \beta$ knock-out mice display impaired performance in cortically mediated processes, suggesting that signaling via this receptor has profound effects on cortical neuron function. However, the effect of rapid signaling via ER $\beta$ on dendritic spines and the signaling pathways initiated by this receptor in cortical neurons are unknown. Here, we show that activation of ER $\beta$ with the specific agonist WAY-200070 results in increased spine density and PSD-95 (postsynaptic density-95) accumulation in membrane regions. Activation of ER $\beta$ by WAY-200070 also resulted in the phosphorylation of p21-activated kinase (PAK) and extracellular signalregulated kinase 1/2 (ERK1/2) in cultured cortical neurons, suggesting a mechanism for the regulation of the actin cytoskeleton. Moreover, we found that aromatase, an enzyme critical for estrogen production, is present at presynaptic termini, supporting a role for brain-synthesized estrogen as a neuromodulator in the cortex. These results implicate ER $\beta$ signaling in controlling dendritic spine morphology, in part via a PAK/ERK1/2-dependent pathway, and provide mechanistic insight into the rapid cellular effects of estrogen on brain function.

\section{Introduction}

In the mammalian forebrain, dendritic spine morphogenesis is an important constituent of structural plasticity (Segal, 2005), and modulating dendritic spine shape and number is thought to underlie information processing and storage in the cortex (Holtmaat and Svoboda, 2009). Conversely, abnormal structural plasticity has been strongly associated with many neuropathologies (Fiala et al., 2002), highlighting the importance of appropriate regulation of these structures for neuronal function. Signaling via Rho family (Rac/Cdc42) and Ras family (Ras/Rap) small GTPases potently regulates cytoskeletal rearrangement necessary for modification of spine morphology (Penzes et al., 2008; Srivastava et al., 2008). Downstream targets of these small GTPases include p21-activated kinase (PAK) and B-Raf, and both kinases have been shown to be involved in mediating changes in structural plasticity (Jones et al., 2009; Woolfrey et al., 2009). Regulation of these pathways is thought to be an important mechanism for regulating spine morphology.

The role of estrogen in modulating dendritic spine remodeling has been well established (Woolley, 2007; Srivastava et al.,

\footnotetext{
Received June 24, 2010; revised Aug. 9, 2010; accepted Aug. 13, 2010.

This work was supported by National Institutes of Health Grant R01MH 071316, the Alzheimer's Association, the National Alliance for Research on Schizophrenia and Depression, and the National Alliance for Autism Research (P.P.); an American Heart Association Postdoctoral Fellowship (D.P.S.); and an American Heart Association Predoctoral Fellowship (K.M.W.). We thank Kelly Jones and Igor Rafalovich for editing.

Correspondence should be addressed to Deepak P. Srivastava or Peter Penzes, Ward 7-174, Department of Physiology, Northwestern University Feinberg School of Medicine, 303 E. Chicago Avenue, Chicago, IL 60611. E-mail: d-srivastava@northwestern.edu or p-penzes@northwestern.edu.

DOI:10.1523/JNEUROSCI.3264-10.2010

Copyright $\odot 2010$ the authors $\quad$ 0270-6474/10/3013454-07\$15.00/0
}

2008). Furthermore, aromatase, a key enzyme required for estrogen production, has been found in the cortex (Yague et al., 2006), leading to the suggestion that brain-synthesized estrogen can rapidly affect neuronal function (Balthazart and Ball, 2006). However, the effect of rapid signaling through estrogen receptor $\beta$ $(\mathrm{ER} \beta)$ in cortical neurons is not known. $\mathrm{ER} \beta$ is abundantly expressed in the cortex (Mitra et al., 2003) and has been shown to be important for memory and hippocampal synaptic plasticity (Liu et al., 2008). ER $\beta$ knock-out mice display impaired learning (Liu et al., 2008), in addition to depressive and anxious behavioral phenotypes (Hughes et al., 2008), suggesting that ER $\beta$ signaling may play a role in these cortically mediated behaviors. However, the effects of ER $\beta$-mediated signaling on dendritic spines of cortical neurons and the underlying molecular mechanisms are unknown.

Here, we show that activation of $\operatorname{ER} \beta$ in cortical neurons by WAY-200070 (herein referred to as 070) results in increased dendritic spine density and clustering of PSD-95 (postsynaptic density$95)$ at the membrane. Signaling via ER $\beta$ also resulted in activation of a PAK/ERK1/2 (extracellular signal-regulated kinase 1/2) signaling pathway. Furthermore, we find that aromatase is enriched at synapses of cortical neurons. These data suggest that signaling through $\mathrm{ER} \beta$ results in rapid modification of dendritic spines of cortical neurons, supporting the role of brain-synthesized estrogen as a postsynaptic morphogen.

\section{Materials and Methods}

Cell cultures and transfections. Dissociated cultures of primary cortical neurons were prepared from embryonic day 18 Sprague Dawley rat embryos (Woolfrey et al., 2009). Neurons were transfected with pEGFP-N2 using Lipofectamine 2000 (Invitrogen) at 24 days in vitro (DIV24) for 

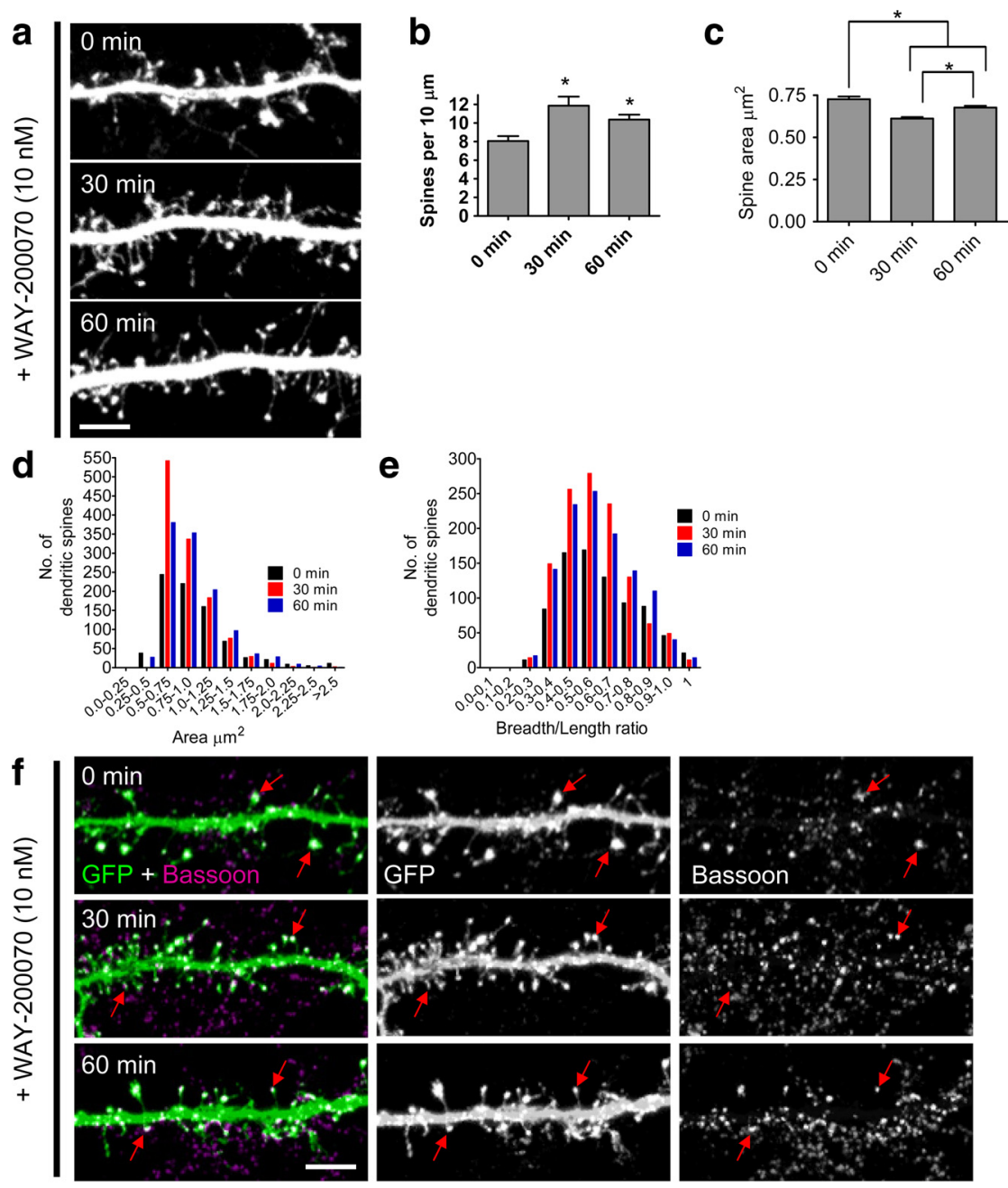

g

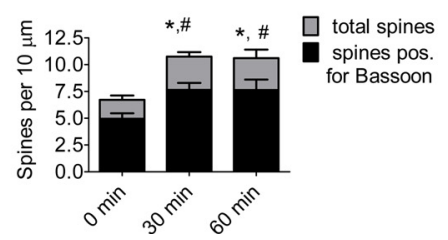

Figure 1. Activation of $\mathrm{ER} \beta$ with 070 results in dendritic spine remodeling. $\boldsymbol{a}$, Time course of dendritic spine morphogenesis in response to $10 \mathrm{~nm} 070$. Cultured cortical neurons (DIV25) expressing EGFP were treated with $10 \mathrm{~nm} 070$ in artificial CSF containing 2-amino-5-phosphonovaleric acid for $0-60 \mathrm{~min}$. $\boldsymbol{b}, \boldsymbol{c}$, Quantification of dendritic spine morphogenesis in $\boldsymbol{a}$. $\boldsymbol{d}, \boldsymbol{e}$, Histograms of spines area and breadth-to-length ratio show that 070 -treated neurons have an increase in spines with smaller areas and lower breadth-to-length ratios. $\boldsymbol{f}, \boldsymbol{g}, 070$ treatment results in an increase in total spine density and number of spines forming contacts with the presynaptic termini. ${ }^{\#, *} p<0.001$. Scale bars, $5 \mu \mathrm{m}$.

48 h. Cells were then treated with 10 nм 070 (synthesized by Wyeth Chemical and Screening Sciences) before being processed for immunocytochemistry or biochemistry (Srivastava et al., 2008).

Quantitative analysis of spine morphology. Images of immunostained neurons were obtained with a confocal microscope using a $63 \times$ oilimmersion objective (numerical aperture $=1.4$ ). Two-dimensional maximum projection reconstructions of images, morphometric analysis (area, length, and breadth), and quantification were done with MetaMorph software (Universal Imaging). Between 9 and 12 neurons from three experiments were analyzed. Experiments were done blind to condition, and on sister cultures. Fluorescence intensities of phosphorylated or endogenous proteins were quantified as described previously (Woolfrey et al., 2009). Statistical analyses (one-way ANOVA) were performed in SPSS (SPSS Inc.).

Biochemistry. Subcellular fractions were prepared by using a ProteoExtract kit (EMD Biosciences), and whole-cell lysates were prepared as described previously (Woolfrey et al., 2009). Lysates were subjected to Western blotting, membranes were probed with the appropriate antibodies, and band intensities were quantified by densitometry using ImageJ.

\section{Results}

Activation of ER $\boldsymbol{\beta}$ induces formation of dendritic spines

EGFP-expressing cortical neurons were treated with the ER $\beta$-specific agonist WAY-070 (10 nM; EC ${ }_{50}$ ER $\beta$ : 2.3 nM vs ER $\alpha$ : 155 nM) (Liu et al., 2008). Treatment with 070 for 30-60 min resulted in an increase in the number of dendritic spines (Fig. 1a,b) (dendritic spine density; 0 min: $8.07 \pm 0.52$ spines per $10 \mu \mathrm{m} ; 30 \mathrm{~min}$ : $11.86 \pm 0.98$ spines per $10 \mu \mathrm{m} ; 60 \mathrm{~min}$ : $10.36 \pm 0.53$ spines per $10 \mu \mathrm{m} ; p<$ $0.001)$. Analysis of dendritic spine morphology revealed a decrease in mean spine area after treatment with 070 . Dendritic spines at $60 \mathrm{~min}$ were significantly larger compared with spines after $30 \mathrm{~min}$ of treatment, but were still significantly smaller than spines at $0 \mathrm{~min}$ (Fig. $1 \mathrm{c}$ ) (spine area; 0 min: $0.73 \pm 0.016 \mu \mathrm{m}^{2}$; $30 \mathrm{~min}: 0.61 \pm$ $0.009 \mu \mathrm{m}^{2} ; 60 \mathrm{~min}: 0.68 \pm 0.011 \mu \mathrm{m}^{2}$; $p<0.001)$. Histograms of spine area confirm an increase in the number of smaller spines (Fig. 1d), suggesting that newly formed spines are smaller than existing spines. The reduction in spine area was driven by a reduction in the average breadth of dendritic spines at $30 \mathrm{~min}$, but not in the average length (supplemental Fig. $1 a$, available at www.jneurosci.org as supplemental material). Interestingly, after 60 min of 070 treatment, the average spine breadth was not significantly different from $0 \mathrm{~min}$, but a trend toward longer spines was seen (supplemental Fig. 1a, available at www.jneurosci.org as supplemental material). To further understand the effect 070 was having on dendritic spine shape, we calculated the breadth-tolength ratio for each spine. This parameter reveals information regarding the spine's shape independent of the spine size: higher values represent stubby (mushroom) shapes, whereas lower values are indicative of thinner/longer spines (supplemental Fig. 1b, available at www.jneurosci.org as supplemental material). After 30 or $60 \mathrm{~min}$ of 070 treatment, the number of spines with lower breadth-to-length ratios increased (Fig. 1e; supplemental Fig. $1 a$, available at www.jneurosci.org as supplemental material), indicating an increase in the prevalence of spines with a thinner/longer morphology. To determine whether ER $\beta$ induced spines were functional, we calculated the number of spines that overlapped with the presynaptic, active zone marker bassoon. Treatment with 070 induced a significant increase in the total number of spines and the number of spines overlapping bassoon (Fig. 1f,g) (total spines vs spines with bassoon; 0 min: 
$6.75 \pm 0.4$ vs $4.95 \pm 0.51$ spines per 10 $\mu \mathrm{m}$; $30 \mathrm{~min}: 10.75 \pm 0.42$ vs $7.6 \pm 0.65$ spines per $10 \mu \mathrm{m} ; 60 \mathrm{~min}: 10.6 \pm 0.79 \mathrm{vs}$ $7.62 \pm 0.9$ spines per $10 \mu \mathrm{m}$; ${ }^{*}$ bassoon positive spines, ${ }^{\star}$ total spines, $\left.p<0.001\right)$. Together, these data demonstrate that treatment with 070 leads to the formation of functional dendritic spines that form presynaptic contacts and are thinner per unit length.

\section{ER $\boldsymbol{\beta}$ activation increases \\ PSD-95 clustering}

PSD-95 is a critical component of mature dendritic spines (Gerrow et al., 2006). Because 070 treatment induces the formation of nascent spines, we investigated whether these spines contained PSD-95. Subcellular fractionation of treated cortical neurons revealed a time-dependent increase in PSD-95 expression in the membrane fraction, paralleled by a timedependent reduction in PSD-95 in the cytosol fraction, suggesting that PSD-95 enriched in the membrane fraction may have moved from the cytosol (Fig. 2a). This pattern of PSD-95 redistribution was supported by line scan analysis of endogenous PSD-95 immunostaining in 070treated cells (supplemental Fig. 2a,b, available at www.jneurosci.org as supplemental material). Immunostaining of endogenous PSD-95 in EGFP-expressing cells demonstrated that there was an overall increase in PSD-95 cluster number after treatment with 070 (supplemental Fig. $2 c$, available at www.jneurosci.org as supplemental material). 070 treatment led to a significant increase in the total number of spines, concurrent with an increase in PSD-95-positive spines. Importantly, in all conditions $>70 \%$ of spines were positive for PSD-95, suggesting that nascent spines did contain PSD-95 (Fig. 2b,c) (total spines vs spines with PSD-95; 0 min: $7.17 \pm 0.33$ vs $5.38 \pm 0.43$ spines per 10 $\mu \mathrm{m} ; 30 \mathrm{~min}: 11.03 \pm 0.32$ vs $7.98 \pm 0.41$ spines per $10 \mu \mathrm{m} ; 60 \mathrm{~min}: 10.56 \pm 0.53 \mathrm{vs}$ $7.62 \pm 0.67$ spines per $10 \mu \mathrm{m}$; ${ }^{\#} \mathrm{PSD}-95$ positive spines, ${ }^{\star}$ total spines, $\left.p<0.001\right)$. Interestingly, 070 treatment did not change the expression of PSD-95 (supplemental Fig. 2d, available at www.jneurosci.org as supplemental material). Closer examination of PSD-95 immunostaining demonstrated that there was an increase in PSD-95 cluster number in spines with a corresponding decrease in PSD-95 cluster number in the dendritic shaft (Fig. $2 d$,e ). Furthermore, there was a reduction in PSD-95 cluster intensity in the dendritic shaft after 070 treatment, consistent with a splitting of PSD-95 clusters in the cytosol (Fig. 2e). These data suggest that 070 induces PSD-95 clustering into nascent spines, likely via the redistribution of pre-existing clusters from the cytosol to new synapses.

a

C
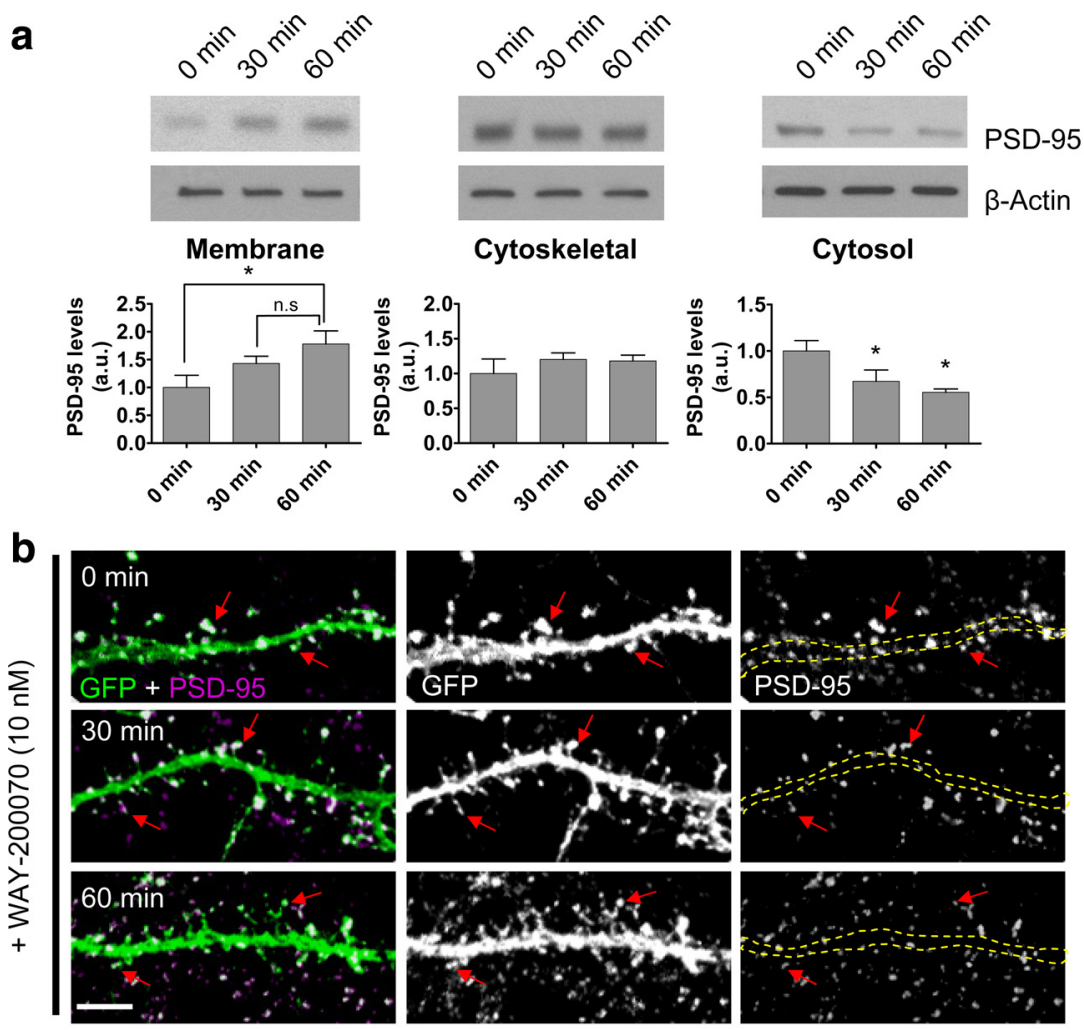

d
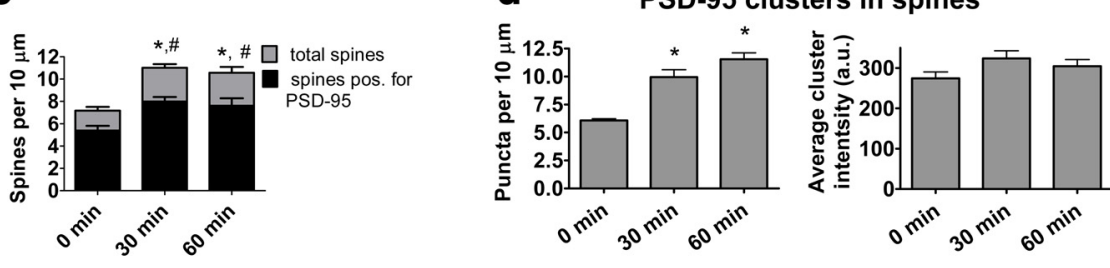

e

PSD-95 clusters in dendrite
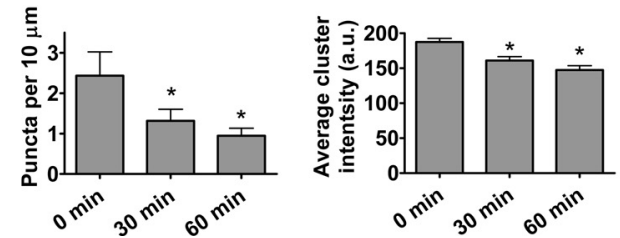

Figure 2. ER $\beta$ activation by 070 mobilizes cytosolic PSD-95, resulting in increased membrane association. $\boldsymbol{a}$, Cortical neurons (DIV24) were treated for 0 - 60 min with 10 nM 070 in artificial CSF containing 2-amino-5-phosphonovaleric acid. Cell fractions were prepared and analyzed by SDS-PAGE. This revealed an increase in PSD-95 in the membrane fraction and a reduction in PSD-95 in the cytosolic fraction after treatment. $\boldsymbol{b}, \boldsymbol{c}$, Treatment with 070 increased total spine numbers and number of spines containing PSD-95. The dendritic shaft is outlined by yellow dashed lines. $\boldsymbol{d}, \boldsymbol{e}$, Analysis of PSD-95 cluster number and intensity in spines and dendritic shaft. "bassoon positive spines, ${ }^{*}$ total spines, $p<0.001$. Scale bars, $5 \mu \mathrm{m}$.

\section{Rapid phosphorylation of PAK by ER $\beta$}

The Rho-like small GTPases Cdc42 and Rac are important regulators of the actin cytoskeleton in neurons (Tada and Sheng, 2006; Penzes et al., 2008). Similarly, Ras and Rap, members of the Ras-like family of small GTPases, also exert profound effects on dendritic spine morphology (Tada and Sheng, 2006; Woolfrey et al., 2009). The serine/threonine kinase, PAK, a downstream target of Cdc42 and Rac, plays an important role in regulating dendritic spine morphology (Jones et al., 2009) and is rapidly activated by estrogen in the hypothalamus (Zhao et al., 2009). B-Raf, a serine/threonine kinase, is a downstream target of both Ras and Rap and has also been implicated in structural modification of dendritic spines (Woolfrey et al., 2009). To investigate 

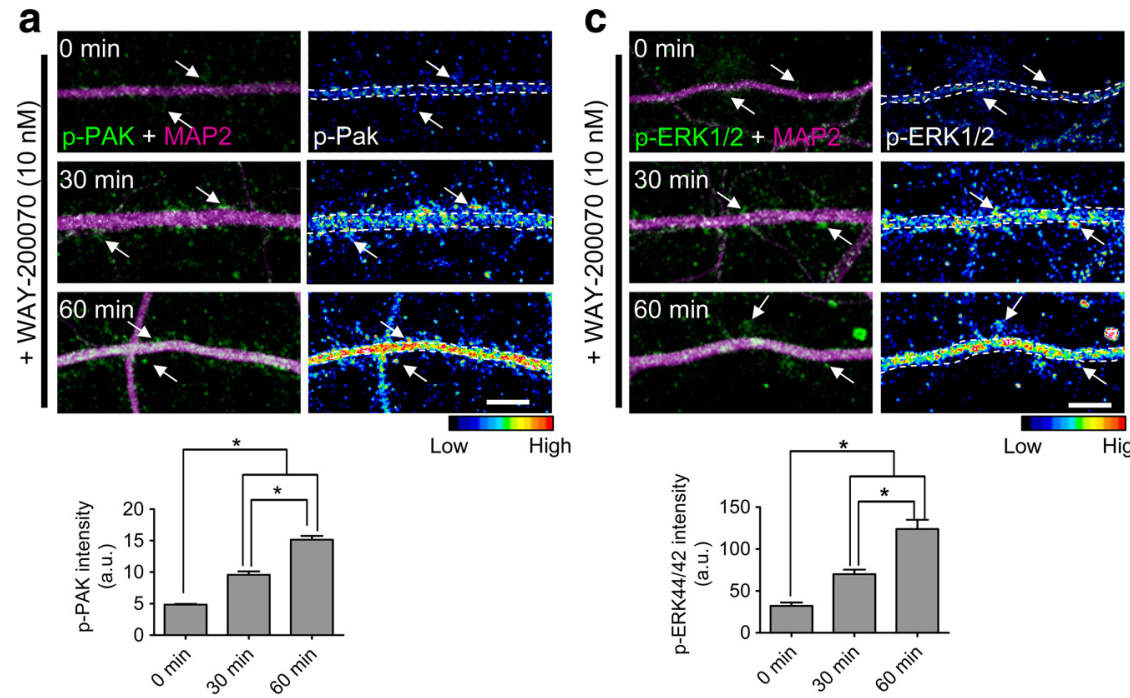

b
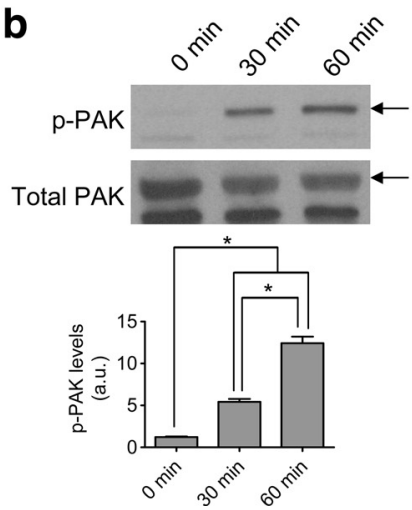

Figure 3. ER $\beta$ activation by 070 induces PAK and ERK1/2 phosphorylation in a time-dependent manner. $\boldsymbol{a}, \mathrm{p}$-PAK levels in the dendrites and spines of cortical neurons after 070 treatment. White dotted lines indicate dendritic shaft, and white arrows indicate dendritic spines. $\boldsymbol{b}$, Representative Western blot of p-PAK levels after treatment with 070 . c, p-ERK1/2 levels in the dendrites and spines increases with time after treatment with 070 . White dotted lines indicate dendritic shaft, and white arrows indicate dendritic spines. $\boldsymbol{d}$, Representative Western blot of $\mathrm{p}$-ERK1/2 levels after treatment with 070 . ${ }^{*} p<0.001$. Scale bars: $5 \mu \mathrm{m}$.

(Thomas and Huganir, 2004). Furthermore, activation of CaMKII $\alpha\left(\mathrm{Ca}^{2+} /\right.$ calmodulin-dependent protein kinase $\mathrm{II} \alpha$ ) is important in regulating activitydependent spine changes (Penzes et al., 2008). Acute estrogen treatment has been shown to activate ERK1/2 and CaMKII $\alpha$ in cortical and hippocampal neurons (O'Neill et al., 2008; Srivastava et al., 2008). Because CaMKII $\alpha$ activity can lead to PAK activation, and ERK1/2 is downstream of PAK activation, we reasoned that signaling via $\mathrm{ER} \beta$ could lead to activation of CaMKII $\alpha$, ERK1/2, or both. Cortical neurons treated with 070 were immunostained for p-ERK1/2; these cells displayed a timedependent increase in ERK1/2 phosphorylation in the dendritic shaft and in spines (Fig. $3 c$ ) ( $p$-ERK1/2 levels; 0 min: $32.13 \pm$ 4.07 arbitrary units; $30 \mathrm{~min}: 69.98 \pm 5.42$ arbitrary units; 60 min: $123.99 \pm 10.76$ arbitrary units; $p<0.001$ ). This was further confirmed by Western blot analysis of cortical neurons treated with 070 (Fig. 3d). No increases in p-CaMKII $\alpha$ levels were seen in 070-treated cells by immunostaining (supplemental Fig. 4a,b, available at www. jneurosci.org as supplemental material). This was supported by Western blotting of cortical cell lysates treated with 070 (supplemental Fig. $4 c$, available at www.jneurosci. org as supplemental material). These data suggest that 070 activation of $\mathrm{ER} \beta$ results in activation of ERK1/2, but not CaMKII $\alpha$, in cortical neurons.

\section{Localization of aromatase in} cortical neurons

Aromatase is the key enzyme in the con-

whether signaling via ER $\beta$ could lead to the phosphorylation of (i.e., activation of) either PAK (p-PAK) or B-Raf ( $\mathrm{p}-\mathrm{B}-\mathrm{Raf})$, we immunostained treated cortical neurons for either $\mathrm{p}-\mathrm{PAK}$ or p-B-Raf. Neurons treated with 070 demonstrated a timedependent increase in p-PAK levels in the dendritic shaft and in spines (Fig. $3 a$ ) (p-PAK levels; 0 min: $4.84 \pm 0.12$ arbitrary units; 30 min: $9.58 \pm 0.52$ arbitrary units; $60 \mathrm{~min}: 15.14 \pm 0.59$ arbitrary units; $p<0.001)$. Western blotting of treated cortical neurons confirmed the time-dependent increase in $\mathrm{p}$-PAK levels (Fig. $3 b$ ). Conversely, immunostaining of treated neurons for $\mathrm{p}-\mathrm{B}$-Raf revealed that there was no change in $\mathrm{p}-\mathrm{B}-\mathrm{R}$ aflevel (supplemental Fig. 3a,b, available at www.jneurosci.org as supplemental material). Western blotting of cell lysates of treated cells confirmed that there was no increase in p-B-Raf levels after ER $\beta$ activation (supplemental Fig. $3 c$, $d$, available at www.jneurosci.org as supplemental material). Together, these data demonstrate that activation of $E R \beta$ results in activation of a PAK-dependent pathway that may lead to the regulation of the actin cytoskeleton.

\section{ERK1/2, but not CaMKII $\alpha$, is phosphorylated in response to $\mathrm{ER} \boldsymbol{\beta}$ activation}

The MAP (mitogen-activated protein) kinases ERK1/2 have been shown to be important in the formation of memory and are strongly associated with structural changes in dendritic spines version of androgens into estrogen. Previous studies have detected aromatase in several areas of the brain, including the cortex and hippocampus (Yague et al., 2006). Inhibition of aromatase activity results in a reduction of spine density in hippocampal neurons (Kretz et al., 2004), leading to the suggestion that brainsynthesized estrogen can rapidly act on postsynaptic structures. However, the precise subcellular localization in cortical neurons is not known. In cortical neurons, we found that aromatase colocalized with the synaptic markers PSD-95 and bassoon, indicating enrichment at synapses (Fig. $4 a, b$ ). Quantification of colocalization shows that a substantial amount of aromatase is present at synapses, in addition to other subcellular compartments (Fig. $4 c, d$ ). In areas that did not contain dendrites, aromatase was found to colocalize with bassoon and the axonal marker tau5, indicating that a portion of aromatase is present at presynaptic terminals (Fig. 4e,f). Together, these data demonstrate a strong presence of aromatase at synapses and presynaptic terminals, consistent with the idea that estrogen produced in the cortex can act on postsynaptic structures.

\section{Discussion}

Recent studies have shown that estrogen can rapidly influence dendritic spine structure in multiple brain regions, including the cortex and hippocampus (Mukai et al., 2007; Srivastava et al., 
2008). This structural plasticity induction is in line with estrogen's ability to rapidly influence synaptic functional plasticity and learning behaviors (Woolley, 2007; Liu et al., 2008). Our data reveal that signaling through $\mathrm{ER} \beta$ in cortical neurons results in an increase in the number of dendritic spines and the phosphorylation of PAK and ERK1/2, two kinases that have been shown to be important for remodeling of dendritic spines. Furthermore, we found that aromatase has a strong presence at cortical neuron synapses, supporting a role for brain-synthesized estrogen as a neuromodulator. Together, these data support a role for the $\mathrm{ER} \beta$ receptor in mediating estrogen's rapid effects on dendritic spines, likely through a PAK/ ERK1/2-dependent pathway (supplemental Fig. 5, available at www. jneurosci.org as supplemental material).

We have shown previously that treatment of cortical neurons with $17 \beta$ estradiol (the biologically active form of estrogen) results in a rapid elevation in the number of dendritic spines (Srivastava et al., 2008). Specific activation of $\operatorname{ER} \beta$ by 070 resulted in an increase in the number of dendritic spines, suggesting that this receptor may play some part in the $17 \beta$ estradiol's ability to elevate spine numbers in cortical neurons. In hippocampal neurons, $17 \beta$-estradiol has been shown to increase spine density in a $\operatorname{ER} \alpha$-, but not ER $\beta$-, dependent manner (Mukai et al., 2007). This disparity could be explained by a number of factors. In the study by Mukai et al., they used adult rat hippocampi. We have used cultured neurons grown for 25-28 DIV, which may be more representative of an adolescent time point (Zuo et al., 2005). At this time point, spines are mature in morphology (having a distinct head and containing PSD-95), but are still subject to intense plasticity as compared with adult neurons (Zuo et al., 2005). Because regulators of spine morphology are also developmentally regulated (Penzes et al., 2008), it is possible that the differences seen between these studies could be caused by developmentally regulated mechanisms that govern structural plasticity. For example, in the adult hippocampus, ER $\alpha$-induced spine changes required NMDA receptor activation, whereas ER $\beta$-dependent spine changes in cortical neurons do not. Thus, it is possible that these differences are caused by examining the effects of $\mathrm{ER} \alpha$ - and $\mathrm{ER} \beta$-dependent spine changes in neurons from different brain regions.

Investigation into the effect of 070 on spine shape revealed that concurrent with the formation of new spines there was an increase in the prevalence of thinner spines. This is consistent with novel spine formation, because thinner spines are considered to be less mature than larger spines (Holtmaat and Svoboda, 2009). Interestingly, the average spine after $60 \mathrm{~min}$ of 070 treatment had an intermediate morphology between control and spines $30 \mathrm{~min}$ after treatment. Analysis of the spine morphology in parallel with the breadth-to-length ratio revealed that dendritic spines after $60 \mathrm{~min}$ of $\mathrm{ER} \beta$ activation have a thinner, yet slightly longer, phenotype. This is possibly representative of newly formed spines becoming more mature over time. Therefore, these data suggest that $\mathrm{ER} \beta$ activation leads to an increase in dendritic spine density; newly formed spines are immature in shape after only $30 \mathrm{~min}$ of treatment, but become more mature by 60 min. Importantly, signaling through $\mathrm{ER} \beta$ may play a critical part in the mechanism underlying estrogen's ability to rapidly enhance synaptic plasticity and ultimately learning behaviors.

The scaffold protein PSD-95 is a critical component of synapses. Trafficking of PSD-95 into postsynaptic regions is required for the maturation of filopodia-like protrusions (Gerrow et al., 2006). We observed an increase in the localization of PSD-95 clusters to spines after treatment with 070, without an increase in total PSD-95 levels. Imaging of PSD-95 in EGFP-expressing cells after 070 treatment confirmed that the majority of spines were positive for PSD-95. This redistribution of PSD-95 seems to be driven by the recruitment of cytosolic PSD-95 into nascent spines; there is a concurrent reduction in PSD-95 cluster number and cluster intensity in the dendritic shaft and an increase in PSD-95 clustering in spines, consistent with previous reports of mobile cytosolic PSD-95 clusters that localize to new functional synapses (Gerrow et al., 2006). These data strongly suggest that this redistribution mechanism supplies newly formed dendritic spines with PSD-95. 
The mechanism by which ER $\beta$ can lead to modifications of dendritic spine numbers has not been well established. It has been suggested that the rapid actions of estrogen occurs in part via a membrane-localized ER $\beta$ in neurons. In hippocampal neurons, ER $\beta$ has been suggested to interact with metabotropic glutamate receptors to initiate signaling cascades (Mermelstein and Micevych, 2008), but it remains to be determined whether this is the case in cortical neurons. Signaling through Rho and Ras family small GTPases are major pathways through which extracellular signals can alter dendritic spine shape and number (Tada and Sheng, 2006; Penzes et al., 2008). Treatment with 070 led to an increase in PAK phosphorylation, but had no effect on B-Raf phosphorylation. These data are consistent with the activation of a Cdc42/Rac-dependent, but not a Ras/Rap-dependent, signaling pathway. A previous study in adult rat hippocampus reported that $17 \beta$-estradiol activated a RhoA-dependent pathway, but not PAK (Kramár et al., 2009). These differences could be caused by the use of neurons of different maturity and from different brain regions. Furthermore, it is of note that cultured neurons may offer greater sensitivity for the detection of activated pathways compared with slice preparations, as used in the previous study. Because Kramár et al. did not investigate whether ER $\beta$ activation could lead to PAK activation, further studies are required to determine the nature of the differences between these studies. In the current study, we observed activation of ERK1/2 kinases in the same time frame as PAK activation, suggesting that these two kinases are part of a signaling cascade. Consistent with our data, the small GTPases Cdc42 and Rac, and the kinases PAK and ERK1/2, all have been shown to regulate spine density in response to a number of different stimuli (Thomas and Huganir, 2004; Tada and Sheng, 2006; Penzes et al., 2008). Therefore, our data support the hypothesis that signaling via $\operatorname{ER} \beta$ can lead to the activation of a Cdc42/Rac-dependent pathway that results in PAK and ERK1/2 phosphorylation, ultimately resulting in changes in dendritic spine number. Further studies will be needed to determine the exact contribution of these components to ER $\beta$-dependent estrogen signaling in cortical neurons.

Our previous study showed that $17 \beta$-estradiol only transiently increased spine numbers (Srivastava et al., 2008). In this study we observed that activation of $\mathrm{ER} \beta$ by its specific ligand led to a sustained increase in spine number. Although the basis for these divergent effects is currently unclear, it is interesting to speculate on the following points. First, because selective ER $\beta$ activation fails to mimic $17 \beta$-estradiol's effects on dendritic spines, it is plausible that a second, $\mathrm{ER} \beta$-independent mechanism is activated after $17 \beta$-estradiol treatment, resulting in the preferential elimination of newly formed spines. Because we have investigated only activation of $\mathrm{ER} \beta$ in this study, it is unclear what role signaling via other estrogen receptors may play in this process. Furthermore, it is possible that these disparate effects are caused by differential rates of metabolism of 070 and $17 \beta$ estradiol or differential binding kinetics of these agonists to $\operatorname{ER} \beta$. Further studies will have to be performed to fully understand the relative contribution of all of the estrogen receptors and whether they work in concert or in opposition to produce $17 \beta$-estradiol's rapid effects on structural plasticity.

Consistent with a role of brain-synthesized estrogen in the cortex, our data demonstrate that aromatase is enriched at synapses and localizes to presynaptic structures in cortical neurons. This suggests that a proportion of brain-synthesized estrogen in the cortex may be produced presynaptically, leading to the presence of high concentrations of estrogen that can act on postsynaptic structures. It is also interesting to note that we observed colocalization of aromatase with PSD-95, suggesting that some estrogen may be produced on the postsynaptic side. Whether the estrogen produced on the postsynaptic side could act in a paracrine manner will require further examination. Nevertheless, the presence of presynaptic aromatase supports a role for estrogen as a cortical neuromodulator acting on postsynaptic structures (Balthazart and Ball, 2006; Srivastava et al., 2008).

The findings in this study build on previous reports that ER $\beta$ may be important for the encoding of memory (Liu et al., 2008; Walf et al., 2008). A number of reports have also suggested that estrogen may have beneficial effects for a variety of neuropsychiatric disorders, such as schizophrenia, depression, and anxiety (Hughes et al., 2008; Kulkarni et al., 2008). Because abnormal spine morphology has been associated with a number of neuropsychiatric disorders (Fiala et al., 2002), it is interesting to suggest that regulation of dendritic spine remodeling may confer some of the benefits seen after estrogen administration in a number of reports studying neuropsychiatric disorders. Understanding the pathways that underlie estrogen's effects on spines may offer novel therapeutic targets that will allow the regulation of synaptic structures, without the unwanted side effects of long-term estrogen treatment.

\section{References}

Balthazart J, Ball GF (2006) Is brain estradiol a hormone or a neurotransmitter? Trends Neurosci 29:241-249.

Fiala JC, Spacek J, Harris KM (2002) Dendritic spine pathology: cause or consequence of neurological disorders? Brain Res Brain Res Rev 39:29-54.

Gerrow K, Romorini S, Nabi SM, Colicos MA, Sala C, El-Husseini A (2006) A preformed complex of postsynaptic proteins is involved in excitatory synapse development. Neuron 49:547-562.

Holtmaat A, Svoboda K (2009) Experience-dependent structural synaptic plasticity in the mammalian brain. Nat Rev Neurosci 10:647-658.

Hughes ZA, Liu F, Platt BJ, Dwyer JM, Pulicicchio CM, Zhang G, Schechter LE, Rosenzweig-Lipson S, Day M (2008) WAY-200070, a selective agonist of estrogen receptor beta as a potential novel anxiolytic/antidepressant agent. Neuropharmacology 54:1136-1142.

Jones KA, Srivastava DP, Allen JA, Strachan RT, Roth BL, Penzes P (2009) Rapid modulation of spine morphology by the 5-HT2A serotonin receptor through kalirin-7 signaling. Proc Natl Acad Sci USA 106: 19575-19580.

Kramár EA, Chen LY, Brandon NJ, Rex CS, Liu F, Gall CM, Lynch G (2009) Cytoskeletal changes underlie estrogen's acute effects on synaptic transmission and plasticity. J Neurosci 29:12982-12993.

Kretz O, Fester L, Wehrenberg U, Zhou L, Brauckmann S, Zhao S, PrangeKiel J, Naumann T, Jarry H, Frotscher M, Rune GM (2004) Hippocampal synapses depend on hippocampal estrogen synthesis. J Neurosci 24:5913-5921.

Kulkarni J, de Castella A, Fitzgerald PB, Gurvich CT, Bailey M, Bartholomeusz C, Burger H (2008) Estrogen in severe mental illness: a potential new treatment approach. Arch Gen Psychiatry 65:955-960.

Liu F, Day M, Muñiz LC, Bitran D, Arias R, Revilla-Sanchez R, Grauer S, Zhang G, Kelley C, Pulito V, Sung A, Mervis RF, Navarra R, Hirst WD, Reinhart PH, Marquis KL, Moss SJ, Pangalos MN, Brandon NJ (2008) Activation of estrogen receptor-beta regulates hippocampal synaptic plasticity and improves memory. Nat Neurosci 11:334-343.

Mermelstein PG, Micevych PE (2008) Nervous system physiology regulated by membrane estrogen receptors. Rev Neurosci 19:413-424.

Mitra SW, Hoskin E, Yudkovitz J, Pear L, Wilkinson HA, Hayashi S, Pfaff DW, Ogawa S, Rohrer SP, Schaeffer JM, McEwen BS, Alves SE (2003) Immunolocalization of estrogen receptor beta in the mouse brain: comparison with estrogen receptor alpha. Endocrinology 144:2055-2067.

Mukai H, Tsurugizawa T, Murakami G, Kominami S, Ishii H, Ogiue-Ikeda M, Takata N, Tanabe N, Furukawa A, Hojo Y, Ooishi Y, Morrison JH, Janssen WG, Rose JA, Chambon P, Kato S, Izumi S, Yamazaki T, Kimoto T, Kawato S (2007) Rapid modulation of long-term depression and spinogenesis via synaptic estrogen receptors in hippocampal principal neurons. J Neurochem 100:950-967. 
O’Neill EE, Blewett AR, Loria PM, Greene GL (2008) Modulation of alphaCaMKII signaling by rapid ERalpha action. Brain Res 1222:1-17.

Penzes P, Cahill ME, Jones KA, Srivastava DP (2008) Convergent CaMK and RacGEF signals control dendritic structure and function. Trends Cell Biol 18:405-413.

Segal M (2005) Dendritic spines and long-term plasticity. Nat Rev Neurosci $6: 277-284$.

Srivastava DP, Woolfrey KM, Woolfrey K, Jones KA, Shum CY, Lash LL, Swanson GT, Penzes P (2008) Rapid enhancement of two-step wiring plasticity by estrogen and NMDA receptor activity. Proc Natl Acad Sci U S A 105:14650-14655.

Tada T, Sheng M (2006) Molecular mechanisms of dendritic spine morphogenesis. Curr Opin Neurobiol 16:95-101.

Thomas GM, Huganir RL (2004) MAPK cascade signalling and synaptic plasticity. Nat Rev Neurosci 5:173-183.

Walf AA, Koonce CJ, Frye CA (2008) Estradiol or diarylpropionitrile administration to wild type, but not estrogen receptor beta knockout, mice enhances performance in the object recognition and object placement tasks. Neurobiol Learn Mem 89:513-521.

Woolfrey KM, Srivastava DP, Photowala H, Yamashita M, Barbolina MV, Cahill ME, Xie Z, Jones KA, Quilliam LA, Prakriya M, Penzes P (2009) Epac2 induces synapse remodeling and depression and its diseaseassociated forms alter spines. Nat Neurosci 12:1275-1284.

Woolley CS (2007) Acute effects of estrogen on neuronal physiology. Annu Rev Pharmacol Toxicol 47:657-680.

Yague JG, Muñoz A, de Monasterio-Schrader P, Defelipe J, Garcia-Segura LM, Azcoitia I (2006) Aromatase expression in the human temporal cortex. Neuroscience 138:389-401.

Zhao Z, Park C, McDevitt MA, Glidewell-Kenney C, Chambon P, Weiss J, Jameson JL, Levine JE (2009) p21-Activated kinase mediates rapid estradiol-negative feedback actions in the reproductive axis. Proc Natl Acad Sci U S A 106:7221-7226.

Zuo Y, Lin A, Chang P, Gan WB (2005) Development of long-term dendritic spine stability in diverse regions of cerebral cortex. Neuron 46:181-189. 